\title{
Re-excision and survival following breast conserving surgery in early stage breast cancer patients: a population-based study
}

\author{
Stacey Fisher ${ }^{1}$, Yutaka Yasui ${ }^{1}$, Kelly Dabbs ${ }^{2}$ and Marcy Winget ${ }^{1,3^{*}}$
}

\begin{abstract}
Background: Increasing population-based evidence suggests that patients who receive breast conserving surgery (BCS) plus radiotherapy have superior survival than those who receive mastectomy. It is unclear, however, how BCS followed by re-excision is associated with all-cause and breast cancer-specific mortality, and whether the BCS survival advantage is maintained if re-excision is needed. The aim of this study was to investigate the clinical, patient, provider and geographic variation associated with receipt of re-excision surgery, and to examine the relationship between re-excision and all-cause and breast cancer-specific mortality.
\end{abstract}

Methods: All women diagnosed with stage I-III breast cancer in Alberta, Canada from 2002 to 2009 were identified from the Alberta Cancer Registry, of which 11,626 were eligible for study inclusion. Type of first breast cancer surgery after diagnosis, subsequent re-excisions within 1 year, surgeon (anonymized), and hospital were obtained from provincial physician claims data. Multilevel logistic regression with surgeons and hospitals as crossed random effects was used to estimate the adjusted odds ratios of re-excision by the factors of interest. Poisson regression models were fitted to compare all-cause and breast cancer-specific mortality by surgical pattern.

Results: Re-excision surgery was received by $19 \%(N=5659)$ of patients who initially received BCS. The adjusted odds of re-excision varied significantly by geography of surgery, and by individual surgeon among stage I and II patients beyond the variation explained by the factors investigated (Stage I OR standard deviation (SD) =0.43; stage $\| \mathrm{OR} \mathrm{SD}=0.39$ ). Patients who were treated with $\mathrm{BCS}$ plus re-excision surgery with either mastectomy or further BCS had similar all-cause and breast cancer-specific mortality as those treated with BCS without re-excision.

Conclusion: These results suggest that breast cancer patients who are treated with BCS plus re-excision surgery by either mastectomy or further BCS have similar survival as those treated with BCS without re-excision. The significant variation in the likelihood of re-excision by geography and by individual surgeon is concerning, especially given the costs to the patient associated with additional surgery and the financial costs to the health system.

Keywords: Breast cancer surgery, Breast conserving surgery, Population-based, Re-excision, Survival

\section{Background}

Most women diagnosed with early stage breast cancer have the option of receiving either mastectomy or breast conserving surgery (BCS) plus adjuvant radiotherapy, as randomized clinical trials have reported equivalent survival outcomes [1-3]. BCS followed by radiotherapy

\footnotetext{
* Correspondence: mwinget@stanford.edu

${ }^{1}$ School of Public Health, University of Alberta, Edmonton, AB T6G 1C9, Canada

${ }^{3}$ Department of Medicine, School of Medicine, Stanford University, 1265 Welch Rd, Room X214, Stanford, California 94305, USA

Full list of author information is available at the end of the article
}

is generally the preferred treatment option for early stage breast cancer as BCS is less invasive, associated with less morbidity and a better cosmetic outcome than mastectomy [4]. The main disadvantage of this treatment is the risk of positive resection margins that necessitate additional surgery by either further BCS or mastectomy. Re-excision is associated with greater morbidity, patient anxiety, poorer cosmetic outcome, delayed initiation of adjuvant therapies, and increased medical cost $[5,6]$. 
In contrast to the clinical trials reporting equivalent survival outcomes regardless of initial breast cancer surgery choice, population-based studies in the United States and Canada have recently reported poorer survival for patients who receive mastectomy compared to those who receive BCS plus radiotherapy [7-11]. Existing evidence of the relationship between re-excision and mortality is lacking and poor in quality $[12,13]$. The single population-based study to investigate survival after re-excision did not include an examination of breast cancer-specific mortality and used a flawed definition of survival time that introduced immortal time bias [12]. It is therefore unclear whether the observed BCS survival advantage extends to patients who receive re-excision.

The purpose of this study was to: 1) investigate the clinical, patient, provider and geographic factors associated with receipt of re-excision surgery and, 2) examine the relationship between re-excision and all-cause and breast cancer-specific mortality.

\section{Methods}

\section{Study population}

The Alberta Cancer Registry was used to identify women diagnosed with stage I, II or III solid tumor breast cancer (International Classification of Diseases for Oncology [ICD-O-3] code c50 [14]) from 2002 to 2009 in Alberta, Canada who did not have another cancer diagnosis within 6 months, as this may influence treatment decisions. Patients were excluded if they: 1) did not receive breast cancer surgery, 2) had a second primary breast cancer diagnosis prior to surgery, 3) had missing or incomplete billing data, and 4) did not have at least 1 year of follow-up following initial surgery, which was necessary to ensure complete re-excision exposure ascertainment.

\section{Data sources and variables}

Two sources of data were used, the Alberta Cancer Registry and the Alberta Health Physician claims database. The Alberta Cancer Registry is a population-based cancer surveillance system, that has been awarded the highest level of certification in all years of the study for its high level of completeness and timeliness of data collection and reporting. The Alberta Health Physician claims database collects information about all procedures performed by fee-for-service physicians for billing purposes. All surgeons performing breast cancer resections in Alberta are paid on a fee-for-service basis. All patient information was de-identified, and physical and technological safeguards were put in place to protect the confidentiality of information and the privacy of patients as per the Alberta Health Information Act.

Demographic, clinical and treatment information were obtained from the Alberta Cancer Registry including: date of and age at diagnosis; geographic region of surgery; cancer stage; tumor size; nodal status; estrogen and progesterone receptor (ER/PR) status; receipt of neoadjuvant and adjuvant chemotherapy; receipt of hormone therapy; receipt of post-operative radiotherapy; date and cause of death. Geographic region of surgery was categorized into the five administrative health zones of Alberta. Two zones are urban and suburban in population size and density (Edmonton and Calgary) and three zones are a combination of suburban, rural and remote regions (South, Central and North). Cancer stage was determined using the American Joint Committee on Cancer (AJCC) 5th edition staging rules active for years 2002 and 2003, and the 6th edition for years 2004-2009 [15, 16]. Patients diagnosed in 2002 and 2003 who received hormone therapy were classified as ER/PR positive, while those who did not were classified as ER/ PR negative, since ER/PR status was not collected by the registry in these years. Patients with missing tumor size $(N=194)$ or nodal status $(N=161)$ were randomly assigned a value proportionally based on the nonmissing information. The following sensitivity analyses were run to test the assumptions: 1) patients with missing tumor size were randomly assigned to be T4 and, 2) patients with missing nodal status were assigned to be N3. Results from the sensitivity analyses did not differ from those of the primary analyses. The North American Association of Central Cancer Registries has awarded the Alberta Cancer Registry the highest level of certification in all years of the study for its high level of completeness and timeliness of data collection and reporting.

Alberta Health Physician Claims data were used to identify the first breast cancer surgery after diagnosis and subsequent re-excision procedures up to 1 year after initial surgery; date and type of surgery, surgical hospital; and anonymized physician identifier were obtained. Surgery pattern, i.e. type(s) of breast cancer surgeries received, including re-excision, was classified as BCS without re-excision, BCS plus BCS re-excision, BCS plus mastectomy re-excision and initial mastectomy. Surgeon volume was defined by the number of breast surgeries performed on patients in the study cohort in each surgeon's highest volume year during the study period, excluding re-excision surgeries. This variable is described in detail elsewhere [17].

\section{Statistical analyses: Re-excision receipt}

Descriptive statistics were calculated for the demographic and clinical characteristics of patients whose initial surgery was BCS by cancer stage. Multi-level mixed effects logistic regression with surgeons and hospitals as crossed random effects [18] were used to estimate odds ratios of re-excision, stratified by stage, and adjusting for age at diagnosis, geographic region of surgery, surgeon 
volume, year of diagnosis, tumor size and nodal status. Variation of the random effects parameters is reported as the standard deviation of the surgeon and hospital-specific random intercepts. Crossed random effects were necessary as some surgeons operated out of multiple hospitals.

\section{Statistical analyses: Overall survival and breast cancer- specific mortality}

Two additional exclusions were made for the investigation of surgery pattern on overall survival and breast cancer-specific mortality to facilitate the comparison of patients who received standard treatments: 1) patients who did not receive radiotherapy following BCS and 2) patients who received radiotherapy following mastectomy.

Descriptive statistics were calculated for the demographic and clinical characteristics of the study patients by surgery pattern. Overall survival and breast cancerspecific mortality of patients by surgical pattern was compared by Kaplan-Meier and cumulative incidence curves, respectively, with deaths from other causes being treated as competing risks in the cumulative incidence analysis. Patients were followed from 1 year post initial surgery until the earliest of date of death or September 30, 2011. Log-rank and Gray's [19] test statistics were used to assess differences in overall survival and breast cancer-specific mortality, respectively. Poisson regression models were fitted to compare overall survival and breast cancer-specific mortality by surgery pattern, adjusting for geographic region of surgery, year of diagnosis, ER/PR status and hormone therapy, neo-adjuvant and adjuvant chemotherapy, tumor size, nodal status, age during follow-up and time since study start. Multilevel mixed effects models with surgeons and hospitals as crossed random effects [18] were fit; no residual variation by surgeon or hospital was found, therefore, the most parsimonious model is presented. Sensitivity analyses excluding patients with T3/T4 and N2/N3 cancers did not differ from the primary analyses. All statistical analyses were performed using SAS statistical software version 9.3 (SAS Institute Cary, NC, USA) and Stata 12.1 (Stata Corp LP, TX, USA).

\section{Results}

There were 11,626 eligible patients diagnosed with early stage breast cancer from 2002 to 2009 included in the study; a flow diagram of surgeries received by the eligible cohort is displayed in Fig. 1 and demographic, clinical and treatment characteristics in Table 1. Patients who did not receive breast cancer surgery $(N=242)$, had a second primary breast cancer diagnosis prior to surgery $(N=115)$, had missing or incomplete billing data $(N=839)$ or did not have at least 1 year of follow-up following initial surgery $(N=210)$ were excluded.

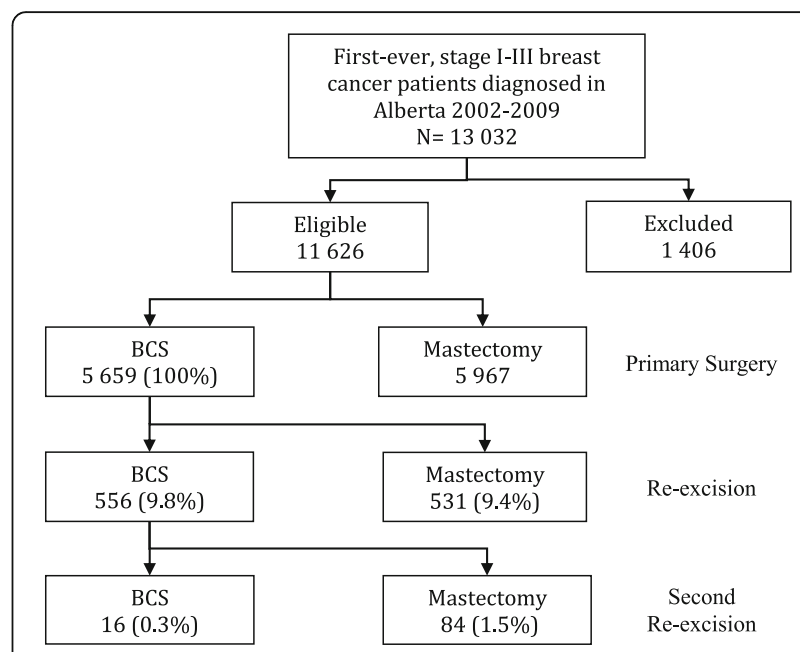

Fig. 1 Flow chart of breast cancer surgeries received by patients in the eligible cohort

BCS without re-excision, BCS plus BCS re-excision, BCS plus mastectomy re-excision and initial mastectomy were received by $39,4,5$ and $51 \%$ of patients, respectively. Older patients were most likely to receive mastectomy, both initially and as a re-excision following initial BCS. BCS plus mastectomy re-excision was more prevalent than BCS plus BCS re-excision in Edmonton and in Central and Southern Alberta, while BCS plus BCS reexcision was more prevalent among patients receiving surgery in Northern Alberta, and performed in approximately equal proportions in Calgary.

\section{Receipt of re-excision}

Patient demographic and clinical characteristics and their associations with re-excision among those who received initial BCS are shown in Table 2. Of the 5659 (49\%) patients who received initial BCS, 1087 (19\%) received re-excision surgery; 16, 23 and $30 \%$ of stage I, II and III cancers, respectively. Regardless of stage, the proportion of patients who received re-excision was lowest for patients $80+$ years of age $(9,16$ and $13 \%$ for stage I, II and III breast cancers, respectively) and when surgery was in Calgary (13, 18 and $24 \%$ for stage I, II and III breast cancers, respectively).

Table 3 displays the stage-specific adjusted odds ratios of re-excision. The adjusted odds of re-excision decreased with age regardless of stage. Patients that received surgery in Calgary had lower adjusted odds of re-excision than those in the other regions of the province; stage III patients treated in Central Alberta had the greatest odds of re-excision (adjusted OR $=4.13,95 \% \mathrm{CI}: 1.07,15.9$ ). Re-excision among stage I (OR standard deviation $(\mathrm{SD})=$ $0.43,95 \%$ CI: $0.30,0.62)$ and II (OR SD $=0.39,95 \%$ CI: $0.25,0.61)$ patients varied significantly by individual 
Table 1 Characteristics of breast cancer patients by surgery pattern

\begin{tabular}{|c|c|c|c|c|}
\hline & \multicolumn{4}{|c|}{ Surgery Pattern } \\
\hline & $\begin{array}{l}\text { BCS Alone } \\
\mathrm{N}(\%)^{\mathrm{a}}\end{array}$ & $\begin{array}{l}\text { BCS, BCS } \\
N(\%)^{\mathrm{a}}\end{array}$ & $\begin{array}{l}\text { BCS, Mastectomy } \\
\mathrm{N}(\%)^{\mathrm{a}}\end{array}$ & $\begin{array}{l}\text { Mastectomy } \\
\mathrm{N}(\%)^{\mathrm{a}}\end{array}$ \\
\hline Total Patients & $4572(39)$ & $472(4)$ & $615(5)$ & $5967(51)$ \\
\hline \multicolumn{5}{|l|}{ Stage } \\
\hline Stage I & $2920(51)$ & $292(5)$ & $264(5)$ & 2242 (39) \\
\hline Stage II & $1412(32)$ & $161(4)$ & $267(6)$ & $2572(58)$ \\
\hline Stage III & $240(16)$ & $19(1)$ & $84(6)$ & $1153(77)$ \\
\hline \multicolumn{5}{|l|}{ Age at Diagnosis } \\
\hline$<50$ & 1205 (39) & $136(4)$ & $227(7)$ & $1541(50)$ \\
\hline $50-59$ & $1342(44)$ & $150(5)$ & $184(6)$ & $1380(45)$ \\
\hline $60-69$ & $1088(42)$ & $114(4)$ & $115(4)$ & $1304(50)$ \\
\hline $70-79$ & $676(34)$ & $60(3)$ & $66(3)$ & $1162(59)$ \\
\hline $80+$ & $258(30)$ & $12(1)$ & $23(3)$ & $580(66)$ \\
\hline \multicolumn{5}{|l|}{ Geography of Surgery } \\
\hline Calgary & $1954(44)$ & $175(4)$ & $185(4)$ & $2138(48)$ \\
\hline Edmonton & $1999(40)$ & $206(4)$ & $295(6)$ & $2468(50)$ \\
\hline Central & $192(23)$ & $23(3)$ & $46(6)$ & $563(68)$ \\
\hline South & $308(33)$ & $36(4)$ & $56(6)$ & $536(57)$ \\
\hline North & $119(27)$ & $32(7)$ & $33(7)$ & $262(59)$ \\
\hline \multicolumn{5}{|l|}{ Surgeon Volume } \\
\hline Very High (60+) & $2313(44)$ & $223(4)$ & $278(5)$ & 2485 (47) \\
\hline High (20-59) & $1700(38)$ & $172(4)$ & $235(5)$ & $2370(53)$ \\
\hline Medium (13-19) & $362(33)$ & $55(5)$ & $67(6)$ & $623(56)$ \\
\hline Low (5-12) & $148(24)$ & $16(3)$ & $28(5)$ & $424(69)$ \\
\hline Very Low $(<5)$ & $49(39)$ & $6(5)$ & $7(6)$ & $65(51)$ \\
\hline \multicolumn{5}{|l|}{ Year of Diagnosis } \\
\hline $2002-2005$ & 2083 (39) & $207(4)$ & $296(6)$ & $2763(52)$ \\
\hline 2006-2009 & $2489(40)$ & $265(4)$ & $319(5)$ & 3204 (51) \\
\hline \multicolumn{5}{|l|}{ Tumor Size } \\
\hline T0 & $2(14)$ & $1(7)$ & $0(0)$ & $11(79)$ \\
\hline $\mathrm{T} 1$ & $3523(48)$ & $358(5)$ & $373(5)$ & $3052(42)$ \\
\hline $\mathrm{T} 2$ & $997(28)$ & $107(3)$ & $200(6)$ & $2235(63)$ \\
\hline T3 & $34(7)$ & $5(1)$ & $38(8)$ & $417(84)$ \\
\hline $\mathrm{T} 4$ & $16(6)$ & $1(0.4)$ & $4(1)$ & $252(92)$ \\
\hline \multicolumn{5}{|l|}{ Nodal Status } \\
\hline No & $3551(47)$ & $353(5)$ & $363(5)$ & $3324(44)$ \\
\hline N1 & $805(28)$ & $102(4)$ & $182(6)$ & $1789(62)$ \\
\hline N2 & $159(21)$ & $13(2)$ & $43(6)$ & $544(72)$ \\
\hline N3 & $57(14)$ & $4(1)$ & $27(7)$ & $310(78)$ \\
\hline \multicolumn{5}{|l|}{ ER/PR Status and Hormone Therapy } \\
\hline ER/PR positive \& received hormone & 3035 (39) & $335(4)$ & $431(6)$ & $3967(51)$ \\
\hline ER/PR positive \& no hormone & 737 (44) & $57(3)$ & $72(4)$ & $807(48)$ \\
\hline ER/PR negative & $800(37)$ & $80(4)$ & $112(5)$ & $1195(55)$ \\
\hline
\end{tabular}

Neo-adjuvant Chemotherapy 
Table 1 Characteristics of breast cancer patients by surgery pattern (Continued)

\begin{tabular}{|c|c|c|c|c|}
\hline & \multicolumn{4}{|c|}{ Surgery Pattern } \\
\hline & $\begin{array}{l}\text { BCS Alone } \\
\mathrm{N}(\%)^{\mathrm{a}}\end{array}$ & $\begin{array}{l}\text { BCS, BCS } \\
N(\%)^{a}\end{array}$ & $\begin{array}{l}\text { BCS, Mastectomy } \\
\mathrm{N}(\%)^{\mathrm{a}}\end{array}$ & $\begin{array}{l}\text { Mastectomy } \\
\mathrm{N}(\%)^{\mathrm{a}}\end{array}$ \\
\hline Not received & $4509(41)$ & $454(4)$ & $537(5)$ & $5571(50)$ \\
\hline Received & $63(13)$ & $18(4)$ & $78(16)$ & $403(81)$ \\
\hline \multicolumn{5}{|c|}{ Adjuvant Chemotherapy } \\
\hline Not received & $3041(42)$ & $307(4)$ & $357(5)$ & $3540(49)$ \\
\hline Received & 1531 (35) & $165(4)$ & $258(6)$ & $2428(55)$ \\
\hline
\end{tabular}

Abbreviations: $B C S$ breast conserving surgery, $E R$ estrogen receptor, $P R$ progesterone receptor

${ }^{\text {a }}$ Row percentages

surgeon, beyond the variation explained by the factors investigated.

\section{Overall survival and breast cancer-specific mortality}

Mortality analysis includes 9023 (78\%) patients: 517 patients who did not receive radiotherapy after BCS and 2086 patients who received radiotherapy after mastectomy were excluded. Median follow-up time was 4.0 years. A total of $880(9.8 \%)$ patients died during the follow-up period: 406 (4.5\%) from breast cancer and 474 (5.3\%) from other causes.

Figure 2 shows Kaplan-Meier and cumulative incidence curves for overall survival and breast cancerspecific mortality, respectively, by surgery pattern. Patients who received initial mastectomy had the greatest risk of all-cause and breast cancer-specific mortality. The five-year all-cause survival probabilities for patients who received BCS without re-excision, BCS plus BCS re-excision, BCS plus mastectomy re-excision and initial mastectomy were 92.5\% (95\% CI: 91.5\%, 93.5\%), 94.7\% (95\% CI: 91.5\%, 96.8\%), 91.2\% (95\% CI: 87.8\%, 94.3\%) and $84.4 \%$ (95\% CI: 83.0\%, 85.7\%), respectively. The fiveyear cumulative incidence of breast cancer death was 3.5\% (95\% CI: $2.9 \%, 4.2 \%$ ), $4.7 \%$ (95\% CI: $2.7 \%, 7.6 \%$ ), 5.3\% (95\%: $3.1 \%, 11.1 \%)$ and 6.8\% (95\% CI: $5.9 \%, 7.8 \%)$ for patients who received BCS without re-excision, BCS plus BCS re-excision, BCS plus mastectomy re-excision and initial mastectomy, respectively.

Adjusted all-cause and breast cancer-specific mortality rate ratios are shown in Table 4. BCS plus BCS re-excision and BCS plus mastectomy re-excision were both associated with similar all-cause and breast cancer-specific mortality as BCS without re-excision. Patients who received initial mastectomy had significantly greater allcause $(\mathrm{HR}=1.35,95 \% \mathrm{CI}: 1.15,1.58)$ and breast cancerspecific $(H R=1.36,95 \% \mathrm{CI}: 1.08,1.72)$ mortality than those who received BCS without re-excision, although confidence intervals were wide for breast cancer-specific mortality. Marginally significantly larger all-cause mortality rate was found in Edmonton ( $\mathrm{HR}=1.17,95 \% \mathrm{CI}$ : 1.01, 1.37) and Southern Alberta $(\mathrm{HR}=1.29,95 \% \mathrm{CI}: 1.02$,
1.61), and significantly larger breast cancer-specific mortality rates were found in Southern $(\mathrm{HR}=1.39,95 \% \mathrm{CI}$ : $1.00,1.93)$ and Northern Alberta (HR $=1.62,95 \%$ CI: 1.05 , 1.93), compared to Calgary. The adjusted all-cause mortality rate decreased from 2002 to 2005 to 2006-2009 (HR = 0.83, 95\% CI: 0.71, 0.98).

\section{Discussion}

In this study, breast cancer patients who were treated with BCS plus re-excision surgery had similar all-cause and breast cancer-specific mortality as those treated with BCS without re-excision. These results supplement increasing observational evidence that in the populationbased context, patients who receive mastectomy have poorer survival than those who receive BCS plus radiotherapy [7-11], suggesting that this survival advantage may extend to patients who receive re-excision surgery by either mastectomy or further BCS. The limited literature that has investigated survival of patients treated with BCS with and without re-excision has also reported comparable overall $[12,13,20]$ and breast cancer-specific [12] survival, however there has been little comparison with initial mastectomy. A large population-based cohort in Denmark found comparable overall survival rates in multivariate analysis among patients treated with BCS with or without re-excision, or initial mastectomy [20]. The association of re-excision and loco-regional recurrence has been investigated more thoroughly, with inconsistent results; re-excision surgery has been associated with increased recurrence risk [13,21, 22], while others have reported no association [23, 24]. Increased recurrence is likely due to residual confounding, but further investigation is necessary to ensure that re-excision is not being performed unnecessarily. Our results suggest that in the population context, re-excision by either BCS or mastectomy does not translate into a measurable survival discrepancy.

The percentage of patients that received re-excision in this study, 19\%, is similar to that found by other population-based studies in England, Ireland and the Netherlands [12, 25, 26]. In Canada, however, re-excision 
Table 2 Characteristics of stage I, II and III breast cancer patients whose initial surgery was BCS and underwent re-excision

\begin{tabular}{|c|c|c|c|c|c|c|}
\hline & Stage I & & Stage II & & Stage III & \\
\hline & $\begin{array}{l}\text { Re-excision } \\
\text { Surgery } \\
N(\%)^{\mathrm{a}}\end{array}$ & Total & $\begin{array}{l}\text { Re-excision } \\
\text { Surgery } \\
N(\%)^{a}\end{array}$ & Total & $\begin{array}{l}\text { Re-excision } \\
\text { Surgery } \\
N(\%)^{\mathrm{a}}\end{array}$ & Total \\
\hline Total Patients & $556(16)$ & 3476 & $428(23)$ & 1840 & $103(30)$ & 343 \\
\hline Age at Diagnosis & & & & & & \\
\hline$<50$ & $176(21)$ & 820 & $145(23)$ & 623 & $42(34)$ & 125 \\
\hline $50-59$ & $166(16)$ & 1031 & $133(25)$ & 535 & $35(32)$ & 110 \\
\hline $60-69$ & $118(14)$ & 862 & $95(24)$ & 391 & $16(25)$ & 64 \\
\hline $70-79$ & $79(14)$ & 582 & $39(20)$ & 194 & $8(28)$ & 29 \\
\hline $80+$ & $17(9)$ & 181 & $16(16)$ & 97 & $2(13)$ & 15 \\
\hline Geography of Surge & & & & & & \\
\hline Calgary & $184(13)$ & 1409 & $143(18)$ & 765 & $33(24)$ & 140 \\
\hline Edmonton & $269(17)$ & 1583 & $188(24)$ & 775 & $44(31)$ & 142 \\
\hline Central & $35(22)$ & 156 & $26(29)$ & 91 & $8(57)$ & 14 \\
\hline South & $43(18)$ & 237 & $38(29)$ & 132 & $11(35)$ & 31 \\
\hline North & $25(27)$ & 91 & $33(43)$ & 77 & $7(44)$ & 16 \\
\hline Surgeon Volume & & & & & & \\
\hline Very High (60+) & $271(15)$ & 1761 & $189(21)$ & 888 & $41(25)$ & 165 \\
\hline High (20-59) & $201(16)$ & 1265 & $167(23)$ & 723 & $39(33)$ & 119 \\
\hline Medium (13-19) & $59(20)$ & 301 & $44(31)$ & 144 & $19(49)$ & 39 \\
\hline Low (5-12) & $21(19)$ & 113 & $21(33)$ & 63 & $2(13)$ & 16 \\
\hline Very Low $(<5)$ & $4(10)$ & 36 & $7(32)$ & 22 & $2(50)$ & 4 \\
\hline Year of Diagnosis & & & & & & \\
\hline $2002-2005$ & $253(16)$ & 1632 & $202(25)$ & 802 & $48(32)$ & 152 \\
\hline 2006-2009 & $303(16)$ & 1844 & $226(22)$ & 1038 & $55(29)$ & 191 \\
\hline Tumor Size & & & & & & \\
\hline T0 & - & - & $0(0)$ & 1 & $1(50)$ & 2 \\
\hline $\mathrm{T} 1$ & $556(16)$ & 3476 & $154(23)$ & 660 & $21(18)$ & 118 \\
\hline $\mathrm{T} 2$ & - & - & $258(22)$ & 1147 & $49(31)$ & 157 \\
\hline $\mathrm{T} 3$ & - & - & $16(50)$ & 32 & $27(60)$ & 45 \\
\hline $\mathrm{T} 4$ & - & - & - & - & $5(24)$ & 21 \\
\hline Nodal Status & & & & & & \\
\hline No & $556(16)$ & 3476 & $158(20)$ & 780 & $2(18)$ & 11 \\
\hline N1 & - & - & $270(25)$ & 1060 & $14(48)$ & 29 \\
\hline N2 & - & - & - & - & $56(26)$ & 215 \\
\hline N3 & - & - & - & - & $31(35)$ & 88 \\
\hline
\end{tabular}

Abbreviations: $B C S$ breast conserving surgery, $E R$ estrogen receptor, $P R$ progesterone receptor

${ }^{a}$ The denominator for each percentage is the total number of patients who received initial BCS in the adjacent row for the same stage of disease

rates have been reported to vary from $17 \%$ in Manitoba and Quebec to 56\% in Newfoundland [27].

Re-excision use varied significantly by geography and surgeon among stage I and II patients in the current study. We believe that this is due to the lack of a formal or informal consensus regarding the best definition of negative surgical margins that adequately reduce the risk of recurrence following BCS at the time of this study
[28]. A survey of Canadian surgeons in 2012 found that $40 \%$ considered a margin negative when 'no tumor cells are seen on the inked margin', while 14, 29 and 18\% required $1 \mathrm{~mm}, 2 \mathrm{~mm}$ and $5 \mathrm{~mm}$ of clear tissue, respectively [29]. Since this study, a consensus guideline for stage I and II breast cancer patients who receive BCS followed with whole breast irradiation has been developed, concluding that margins wider than 'no ink on 
Table 3 Adjusted $^{a}$ odds ratio of re-excision estimates ${ }^{b}$ for stage I, II and III breast cancer patients whose initial surgery was BCS

\begin{tabular}{|c|c|c|c|}
\hline & \multicolumn{3}{|c|}{ Adjusted ${ }^{1}$ Odds Ratios of Re-excision (95\% Cl) } \\
\hline & Stage I & Stage II & Stage III \\
\hline Total Patients & 3476 & 1840 & 343 \\
\hline Age at Diagnosis & $P<0.001$ & $P=0.43$ & $P=0.32$ \\
\hline$<50$ & 1.00 & 1.00 & 1.00 \\
\hline $50-59$ & $0.68(0.54,0.87)$ & $1.07(0.80,1.41)$ & $1.06(0.57,1.97)$ \\
\hline $60-69$ & $0.58(0.44,0.75)$ & $1.09(0.80,1.49)$ & $0.84(0.39,1.80)$ \\
\hline $70-79$ & $0.56(0.42,0.76)$ & $0.85(0.56,1.29)$ & $0.68(0.24,1.90)$ \\
\hline $80+$ & $0.35(0.21,0.60)$ & $0.67(0.37,1.20)$ & $0.21(0.04,1.22)$ \\
\hline Geography of Surgery & $P=0.004$ & $P=0.04$ & $P=0.09$ \\
\hline Calgary & 1.00 & 1.00 & 1.00 \\
\hline Edmonton & $1.74(1.18,2.57)$ & $1.64(1.09,2.45)$ & $2.14(1.07,4.29)$ \\
\hline Central & $2.26(1.27,4.03)$ & $1.62(0.86,3.05)$ & $4.13(1.07,15.9)$ \\
\hline South & $1.74(1.00,3.04)$ & $1.55(0.87,2.75)$ & $2.13(0.77,5.89)$ \\
\hline North & $2.89(1.47,5.68)$ & $2.58(1.34,4.97)$ & $3.79(0.94,15.3)$ \\
\hline Surgeon Volume & $P=0.80$ & $P=0.95$ & $P=0.16$ \\
\hline Very High (60+) & 1.00 & 1.00 & 1.00 \\
\hline High (20-59) & $0.96(0.63,1.45)$ & $0.99(0.65,1.51)$ & $1.40(0.69,2.83)$ \\
\hline Medium (13-19) & $0.96(0.58,1.60)$ & $1.16(0.67,2.00)$ & $1.88(0.71,5.01)$ \\
\hline Low (5-12) & $0.83(0.42,1.66)$ & $1.22(0.59,2.50)$ & $0.24(0.04,1.55)$ \\
\hline Very Low $(<5)$ & $0.51(0.16,1.62)$ & $1.26(0.45,3.54)$ & $1.62(0.18,14.2)$ \\
\hline Year of Diagnosis & $P=0.42$ & $P=0.18$ & $P=0.27$ \\
\hline $2002-2005$ & 1.00 & 1.00 & 1.00 \\
\hline 2006-2009 & $1.08(0.89,1.32)$ & $0.85(0.67,1.07)$ & $0.74(0.43,1.26)$ \\
\hline Tumor Size & & $P<0.001$ & $P<0.001$ \\
\hline $\mathrm{T} 0 / \mathrm{T} 1$ & 1.00 & 1.00 & 1.00 \\
\hline $\mathrm{T} 2$ & - & $1.39(1.04,1.86)$ & $1.40(0.15,12.8)$ \\
\hline T3 & - & $6.33(2.82,14.2)$ & $1.33(0.12,14.2)$ \\
\hline T4 & - & - & $1.83(0.17,19.9)$ \\
\hline Nodal Status & & $P<0.001$ & $P=0.75$ \\
\hline No & 1.00 & 1.00 & 1.00 \\
\hline N1 & - & $1.74(1.30,2.33)$ & $1.40(0.15,12.8)$ \\
\hline N2 & - & - & $1.33(0.12,14.2)$ \\
\hline N3 & - & - & $1.83(0.17,19.9)$ \\
\hline RE Parameter Estimates & & & \\
\hline Hospital & $0(-)$ & $0(-)$ & $0.15(0.00,9.09)$ \\
\hline Surgeon & $0.43(0.30,0.62)$ & $0.39(0.25,0.61)$ & $0(-)$ \\
\hline
\end{tabular}

Abbreviations: $B C S$ breast conserving surgery, $C l$ confidence interval, $R E$ random effects, $S D$ standard deviation

${ }^{a}$ Adjusted for the variables in the table

${ }^{b}$ Multi-level logistic regression with hospitals and surgeons as crossed random effects

tumor' do not further reduce recurrence risk [30]. In the current study, patients who received surgery in the urban region of Calgary were consistently the least likely to receive re-excision; empirical evidence suggests this is due to early encouragement to accept 'no ink on tumor' margins. Regional and surgeon-specific variation may also be explained in part by variation in the use of intraoperative techniques of margin assessment including imaging, routine cavity shaving and frozen section analysis, variation of which has been reported in Canada [29]. Although it is encouraging that no residual variation by surgeon or hospital was found for all-cause or 

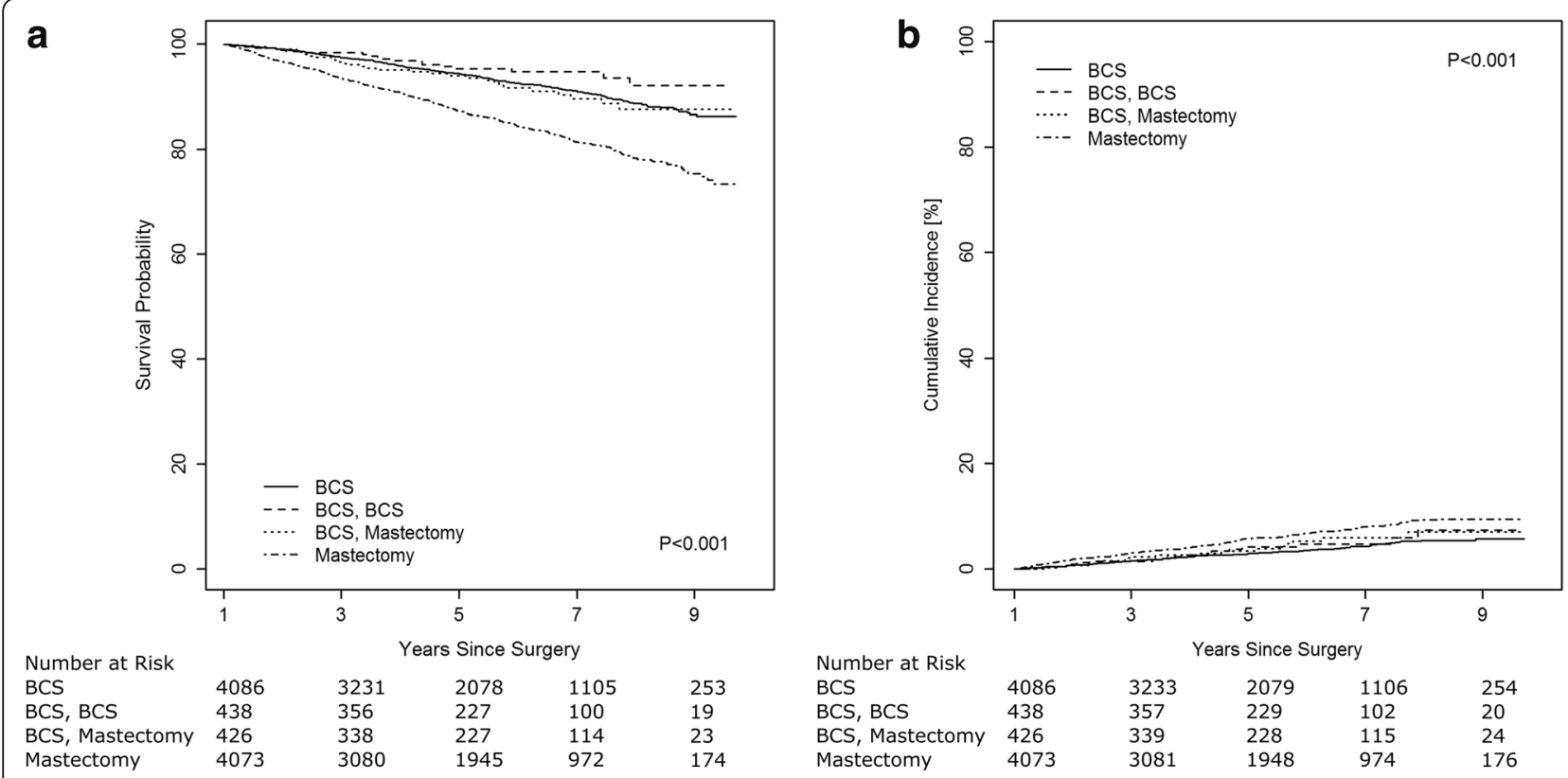

Fig. 2 Kaplan-Meier survival probabilities (a) and cumulative breast cancer mortality (b) by surgery pattern for stage I-III breast cancer patients

breast cancer-specific mortality, the reported geographic variation of all-cause and breast cancer-specific survival is of concern and deserves further investigation.

Surprisingly, re-excision was not associated with surgeon volume, as other studies have reported this association [26], however, other characteristics of the operating surgeon such as years since graduation, foreign training and specialization may be responsible for some of the residual variation by surgeon reported. Residual confounding by unmeasured patient case-mix variables may also explain some of the reported variation by surgeon.

Re-excision was also associated with tumor size and, among patients with stage I disease, younger age at diagnosis. BCS performed on a large tumor is a more technically challenging procedure than that performed on a small tumor as it is more difficult to remove a large amount of tissue and simultaneously optimize cosmetic outcome. Additionally, younger women tend to have dense breasts, limiting the ability of the surgeon to accurately assess tumor extent preoperatively [24]. It has also been suggested that younger patients value a satisfactory cosmetic result more than older patients and, therefore, the initial excision may be inappropriately minimized, thus requiring subsequent surgery [31].

The population perspective of the present study is especially valuable as surgical decisions for breast cancer are based on various factors including patient preference and contraindications to radiotherapy. It is therefore of clinical interest to investigate surgical patterns in a population-based and unselected series of patients with minimal bias caused by variation in access to care often present in alternatively-funded health care systems. Multi-level modeling was used to account for the hierarchical data structure and provide estimates of the level of variation within surgeons and hospitals. Limitations of the current study are largely due to the nature of the administrative datasets; information about margin status, breast density, recurrence and prognostic factors such as comorbidities, lifestyle factors or socioeconomic status were not available. Lack of these variables may introduce confounding by indication if higher risk patients are more likely to receive mastectomy. Additionally, longer follow-up may be necessary to detect survival differences between the surgery pattern groups.

\section{Conclusion}

The current results suggest that patients who receive BCS plus re-excision with either BCS or mastectomy have similar survival outcomes as patients who receive BCS without re-excision. Although not possible in the current study, investigation of recurrence rates and surgical patterns, would be of interest. Given the increasing population-based results favoring initial treatment with BCS plus radiotherapy over mastectomy, and considering that mastectomy is a more invasive procedure, fear of additional surgery should not be a reason to receive initial mastectomy. We suggest greater efforts towards educating and encouraging women to receive initial BCS rather than mastectomy when appropriate. This may be particularly important in the face of increasing mastectomy rates [32,33], including double mastectomy among younger women [34], many of which are likely excellent 
Table 4 Adjusted ${ }^{a}$ Poisson regression models assessing all-cause and breast cancer-specific mortality by surgery pattern for stage I-III breast cancer patients

\begin{tabular}{|c|c|c|}
\hline & \multicolumn{2}{|c|}{$\begin{array}{l}\text { Adjusted }{ }^{a} \text { Mortality Rate Ratio } \\
(95 \% \mathrm{Cl})\end{array}$} \\
\hline & All-Cause & $\begin{array}{l}\text { Breast Cancer- } \\
\text { Specific }\end{array}$ \\
\hline Surgery Pattern & $P<0.001$ & $P=0.07$ \\
\hline BCS & 1.00 & 1.00 \\
\hline $\mathrm{BCS}, \mathrm{BCS}$ & $0.68(0.43,1.09)$ & $1.19(0.71,1.97)$ \\
\hline BCS, Mastectomy & $0.93(0.64,1.36)$ & $1.22(0.74,2.00)$ \\
\hline Mastectomy & $1.35(1.15,1.58)$ & $1.36(1.08,1.72)$ \\
\hline Geography of Surgery & $P=0.11$ & $P=0.14$ \\
\hline Calgary & 1.00 & 1.00 \\
\hline Edmonton & $1.17(1.01,1.37)$ & $1.13(0.90,1.42)$ \\
\hline Central & $1.16(0.89,1.50)$ & $1.10(0.75,1.61)$ \\
\hline South & $1.29(1.02,1.61)$ & $1.39(1.00,1.93)$ \\
\hline North & $1.33(0.96,1.85)$ & $1.62(1.05,2.48)$ \\
\hline Year of Diagnosis & $P=0.024$ & $P=0.89$ \\
\hline $2002-2005$ & 1.00 & 1.00 \\
\hline $2006-2009$ & $0.83(0.71,0.98)$ & $0.98(0.78,1.24)$ \\
\hline $\begin{array}{l}\text { ER/PR Status \& Hormone } \\
\text { therapy }\end{array}$ & $P<0.001$ & $P<0.001$ \\
\hline $\begin{array}{l}\text { ER/PR positive \& received } \\
\text { hormone }\end{array}$ & 1.00 & 1.00 \\
\hline $\begin{array}{l}\text { ER/PR positive \& no } \\
\text { hormone }\end{array}$ & $1.51(1.24,1.84)$ & $1.25(0.88,1.75)$ \\
\hline ER/PR negative & $1.96(1.68,2.30)$ & $2.61(2.10,3.25)$ \\
\hline Neo-adjuvant Chemotherapy & $P=0.11$ & $P=0.030$ \\
\hline Not received & 1.00 & 1.00 \\
\hline Received & $0.73(0.50,1.06)$ & $0.60(0.39,0.94)$ \\
\hline Adjuvant Chemotherapy & $P=0.002$ & $P=0.46$ \\
\hline Not received & 1.00 & 1.00 \\
\hline Received & $1.38(1.12,1.70)$ & $1.11(0.84,1.47)$ \\
\hline Tumor Size & $P<0.001$ & $P<0.001$ \\
\hline T0/T1 & 1.00 & 1.00 \\
\hline T2 & $2.12(1.82,2.47)$ & $2.36(1.85,3.00)$ \\
\hline $\mathrm{T} 3 / \mathrm{T} 4$ & $2.97(2.20,4.01)$ & $4.34(2.95,6.36)$ \\
\hline Nodal Status & $P<0.001$ & $P<0.001$ \\
\hline NO & 1.00 & 1.00 \\
\hline N1 & $1.80(1.52,2.13)$ & $2.35(1.85,3.00)$ \\
\hline N2/N3 & $3.00(2.34,3.86)$ & $4.53(3.27,6.26)$ \\
\hline
\end{tabular}

Abbreviations: $B C S$ breast conserving surgery, $C l$ confidence interval, $E R$ estrogen receptor, $P R$ progesterone receptor

${ }^{a}$ Adjusted for all variables shown in the table, in addition to age during follow-up and time since study start

candidates for BCS. Further work should explore how factors such as possibility of re-excision with BCS and avoidance of radiotherapy with mastectomy influence surgical decision making.
Additionally, although the survival of patients who received re-excision was not significantly different from those who received a single BCS procedure, the significant variation in the likelihood of re-excision by geography and by individual surgeon is concerning, especially given the costs to the patient associated with additional surgery and the financial costs to the health system. We suggest targeted education efforts for surgeons on the recent consensus guidelines to facilitate increasing surgeon uptake, which may help to reduce variation and prevent unnecessary re-excision. Re-evaluation of re-excision rates in Alberta in the coming years will be of interest.

\section{Abbreviations}

BCS: Breast conserving surgery; ER/PR: Estrogen and progesterone receptor; ICD-O: International Classification of Diseases for Oncology; OR: Odds ratio; SD: Standard deviation

\section{Acknowledgements}

Not applicable.

\section{Funding}

This work was supported by a grant from the Canadian Institutes of Health Research (MOP 111236). SF was supported by graduate studentships from the Alberta Cancer Foundation, Alberta Innovates- Health Solutions and the Canadian Institutes of Health Research. Funders had no role in the study design, analysis and interpretation of data, writing of the manuscript or the decision to submit for publication.

\section{Availability of data and materials}

Due to the requirements to sign confidentiality agreements with the data custodians, we are not at liberty to directly share our datasets. All other materials described in the manuscript, including tables and figures, will be freely available to any scientist wishing to use them for non-commercial purposes, without breaching participant confidentiality.

\section{Authors' contributions}

All authors were involved in the conception and design of the study, the interpretation of the results and manuscript revision. SF, YY and MW additionally performed data analysis, and SF drafted the manuscript. All authors read and approved the submitted version.

\section{Ethics approval and consent to participate}

This study was approved by the Health Research Ethics Board of Alberta. Consent to participate was not needed as this was a secondary data analysis based on medical records of the patients available in the population-based administrative health data.

\section{Consent for publication}

Not applicable.

\section{Competing interests}

The authors declare that they have no competing interests.

\section{Publisher's Note}

Springer Nature remains neutral with regard to jurisdictional claims in published maps and institutional affiliations.

\section{Author details}

'School of Public Health, University of Alberta, Edmonton, AB T6G 1C9, Canada. ${ }^{2}$ Department of Surgery, University of Alberta, Edmonton, AB T6G 1C9. Canada. ${ }^{3}$ Department of Medicine, School of Medicine, Stanford University, 1265 Welch Rd, Room X214, Stanford, California 94305, USA. 
Received: 25 April 2017 Accepted: 23 January 2018 Published online: 08 February 2018

\section{References}

1. Jatoi I, Proschan MA. Randomized trials of breast-conserving therapy versus mastectomy for primary breast cancer: a pooled analysis of updated results. Am J Clin Oncol. 2005:28:289-94.

2. Fisher B, Anderson S, Bryant J, Margolese RG, Deutsch M, Fisher ER, et al. Twenty-year follow-up of a randomized trial comparing total mastectomy, lumpectomy, and lumpectomy plus irradiation for the treatment of invasive breast cancer. N Engl J Med. 2002;347:1233-41.

3. van der Hage JA, Putter H, Bonnema J, Bartelink $H$, Therasse $P$, van de Velde $\mathrm{CJH}$, et al. Impact of locoregional treatment on the early-stage breast cancer patients: a retrospective analysis. Eur J Cancer. 2003;39:2192-9.

4. $\mathrm{NIH}$ consensus conference. Treatment of early-stage breast cancer. JAMA. 1991;265:391-5

5. Waljee JF, Hu ES, Newman LA, Alderman AK. Predictors of breast asymmetry after breast-conserving operation for breast cancer. J Am Coll Surg. 2008;206:274-80.

6. Olsen M, Nickel KB, Margenthaler J, Wallace AE, Mines D, Miller JP, et al. Increased risk of surgical site infection among breast-conserving surgery reexcisions. Ann Surg Oncol. 2015;22:2003-9.

7. Fisher S, Gao H, Yasui Y, Dabbs K, Winget M. Survival in stage I-III breast cancer patients by surgical treatment in a publicly funded health care system. Ann Oncol. 2015;26:1161-9.

8. Chen K, Liu J, Zhu L, Su F, Song E, Jacobs LK. Comparative effectiveness study of breast-conserving surgery and mastectomy in the general population: a NCDB analysis. Oncotarget. 2015;6:40127-40.

9. Hwang ES, Lichtensztajn DY, Gomez SL, Fowble B, Clarke CA. Survival after lumpectomy and mastectomy for early stage invasive breast cancer: the effect of age and hormone receptor status. Cancer. 2013;119:1402-11.

10. Kurian AW, Lichtensztajn DY, Keegan THM, Nelson DO, Clarke CA, Gomez SL, et al. Use of and mortality after bilateral mastectomy compared with other surgical treatments for breast cancer in California, 1998-2011. JAMA. 2014:312:902.

11. Agarwal S, Pappas L, Neumayer L, Kokeny K, Agarwal J. Effect of breast conservation therapy vs mastectomy on disease-specific survival for earlystage breast cancer. JAMA Surg. 2014;149:267-74.

12. Vos EL, Jager A, Verhoef C, Voogd AC, Koppert LB. Overall survival in patients with a re-excision following breast conserving surgery compared to those without in a large population-based cohort. Eur J Cancer. 2015;51:282-91.

13. Ali AN, Vapiwala N, Guo M, Hwang W-T, Harris EE, Solin LJ. The impact of reexcision and residual disease on local recurrence after breast conservation treatment for patients with early stage breast cancer. Clin Breast Cancer. 2011;11:400-5

14. Fritz A, Percy C, Jack A, Shanmugaratnam K, Sobin L, Parkin DM, et al. International classification of disease for oncology. 3rd ed. Geneva, Switzerland: World Health Organization; 2000.

15. Fleming, ID. Cooper JS, Henson DE, Hutter RV, Kennedy BJ, Murphy G et al. AJCC cancer staging manual, 5th ed. New York: Springer-Verlag; 1997.

16. Greene FL, Page DL, Fleming ID, Fritz AG, Balch CM, Haller DG, et al. AJCC cancer staging manual. 6th ed. New York: Springer-Verlag; 2002.

17. Fisher S, Yasui Y, Dabbs K, Winget M. Using multilevel models to explain variation in clinical practice: surgeon volume and the surgical treatment of breast cancer. Ann Surg Oncol. 2016;23:1845-51.

18. Press S. STATA multilevel mixed-effects reference manual. TX: College Station; 2017.

19. Gray RJ. A class of K-sample tests for comparing the cumulative incidence of a competing risk. Ann Stat. 1988;16:1141-54.

20. Bodilsen A, Bjerre K, Offersen BV, Vahl P, Ejlertsen B, Overgaard J, et al. The influence of repeat surgery and residual disease on recurrence after breast conserving surgery: a Danish breast cancer cooperative group study. Ann Surg Oncol. 2015;22:S476-85.

21. Hennigs A, Fuchs V, Sinn H-P, Riedel F, Rauch G, Smetanay K, et al. Do patients after Reexcision due to involved or close margins have the same risk of local recurrence as those after one-step breast-conserving surgery? Ann Surg Oncol. 2016:1831-7.

22. Adams BJ, Zoon CK, Stevenson C, Chitnavis P, Wolfe L, Bear HD. The role of margin status and reexcision in local recurrence following breast conservation surgery. Ann Surg Oncol. 2013;20:2250-5.
23. O'Sullivan MJ, Li T, Freedman G, Morrow M. The effect of multiple reexcisions on the risk of local recurrence after breast conserving surgery. Ann Surg Oncol. 2007;14:3133-40.

24. Aziz D, Rawlinson E, Narod SA, Sun P, Lickley HLA, McCready DR, et al. The role of reexcision for positive margins in optimizing local disease control after breast-conserving surgery for cancer. Breast J. 2006;12:331-7.

25. Jeevan $\mathrm{R}$, Cromwell DA, Trivella M, Lawrence G, Kearins O, Pereira J, et al. Reoperation rates after breast conserving surgery for breast cancer among women in England: retrospective study of hospital episode statistics. BMJ. 2012;345:e4505

26. de Camargo CM, Comber H, Sharp L. Hospital and surgeon caseload are associated with risk of re-operation following breast-conserving surgery. Breast Cancer Res Treat. 2013:1-10.

27. Porter G, Wagar B, Bryant H, Hewitt M, Wai E, Dabbs K, et al. Rates of breast cancer surgery in Canada from 2007/08 to 2009/10: retrospective cohort study. CMAJ Open. 2014;2:E102-8.

28. Singletary SE. Surgical margins in patients with early-stage breast cancer treated with breast conservation therapy. Am J Surg. 2002;184:383-93.

29. Lovrics PJ, Gordon M, Cornacchi SD, Farrokhyar F, Ramsaroop A, Hodgson N, et al. Practice patterns and perceptions of margin status for breast conserving surgery for breast carcinoma: National Survey of Canadian general surgeons. Breast. 2012;21:730-4.

30. Moran MS, Schnitt SJ, Giuliano AE, Harris JR, Khan SA, Horton J, et al. Society of Surgical Oncology-American Society for Radiation Oncology consensus guideline on margins for breast-conserving surgery with whole-breast irradiation in stages I and || invasive breast cancer. Ann Surg Oncol. 2014;21:704-16.

31. Vicini FA, Kestin LL, Goldstein NS, Chen PY, Pettinga J, Frazier RC, et al. Impact of young age on outcome in patients with Ductal carcinoma-in-situ treated with breast-conserving therapy. J Clin Oncol. 2000;18:296.

32. Kummerow KL, Du L, Penson DF, Shyr Y, Hooks MA. Nationwide trends in mastectomy for early-stage breast cancer. JAMA Surg. 2015;150:9-16.

33. Mahmood U, Hanlon AL, Koshy M, Buras R, Chumsri S, Tkaczuk KH, et al. Increasing national mastectomy rates for the treatment of early stage breast cancer. Ann Surg Oncol. 2013;20:1436-43.

34. Wong SM, Freedman RA, Sagara Y, Aydogan F, Barry WT, Golshan M. Growing use of Contralateral prophylactic mastectomy despite no improvement in long-term survival for invasive breast cancer. Ann Surg. 2017;265:581-9.

\section{Submit your next manuscript to BioMed Central and we will help you at every step:}

- We accept pre-submission inquiries

- Our selector tool helps you to find the most relevant journal

- We provide round the clock customer support

- Convenient online submission

- Thorough peer review

- Inclusion in PubMed and all major indexing services

- Maximum visibility for your research

Submit your manuscript at www.biomedcentral.com/submit
) Biomed Central 